\title{
Correction to: The deployment of balanced scorecard in health care organizations: is it beneficial? A systematic review
}

Faten Amer ${ }^{1,2^{*}}$, Sahar Hammoud ${ }^{1}$, Haitham Khatatbeh', Szimonetta Lohner ${ }^{3}$, Imre Boncz ${ }^{2}$ and Dóra Endrei ${ }^{2}$

\section{Correction to: BMC Health Serv Res 22, 65 (2022)}

https://doi.org/10.1186/s12913-021-07452-7

Following publication of the original article [1], the authors identified that the arrows were misplaced in Fig. 2 due to a format conversion issue. The correct figure is given below.

The original article has been corrected.

\section{Author details}

${ }^{1}$ Doctoral School of Health Sciences, Faculty of Health Sciences, University of Pécs, Maria u. 5-7, Pécs H-7621, Hungary. ${ }^{2}$ Institute for Health Insurance, Faculty of Health Sciences, University of Pécs, Pécs, Hungary. ${ }^{3}$ Cochrane Hungary, Clinical Center of the University of Pécs, Medical School, University of Pécs, Pécs, Hungary.

Published online: 10 February 2022

\section{Reference}

1. Amer $F$, et al. The deployment of balanced scorecard in health care organizations: is it beneficial? A systematic review. BMC Health Serv Res, 2022;22:65. 


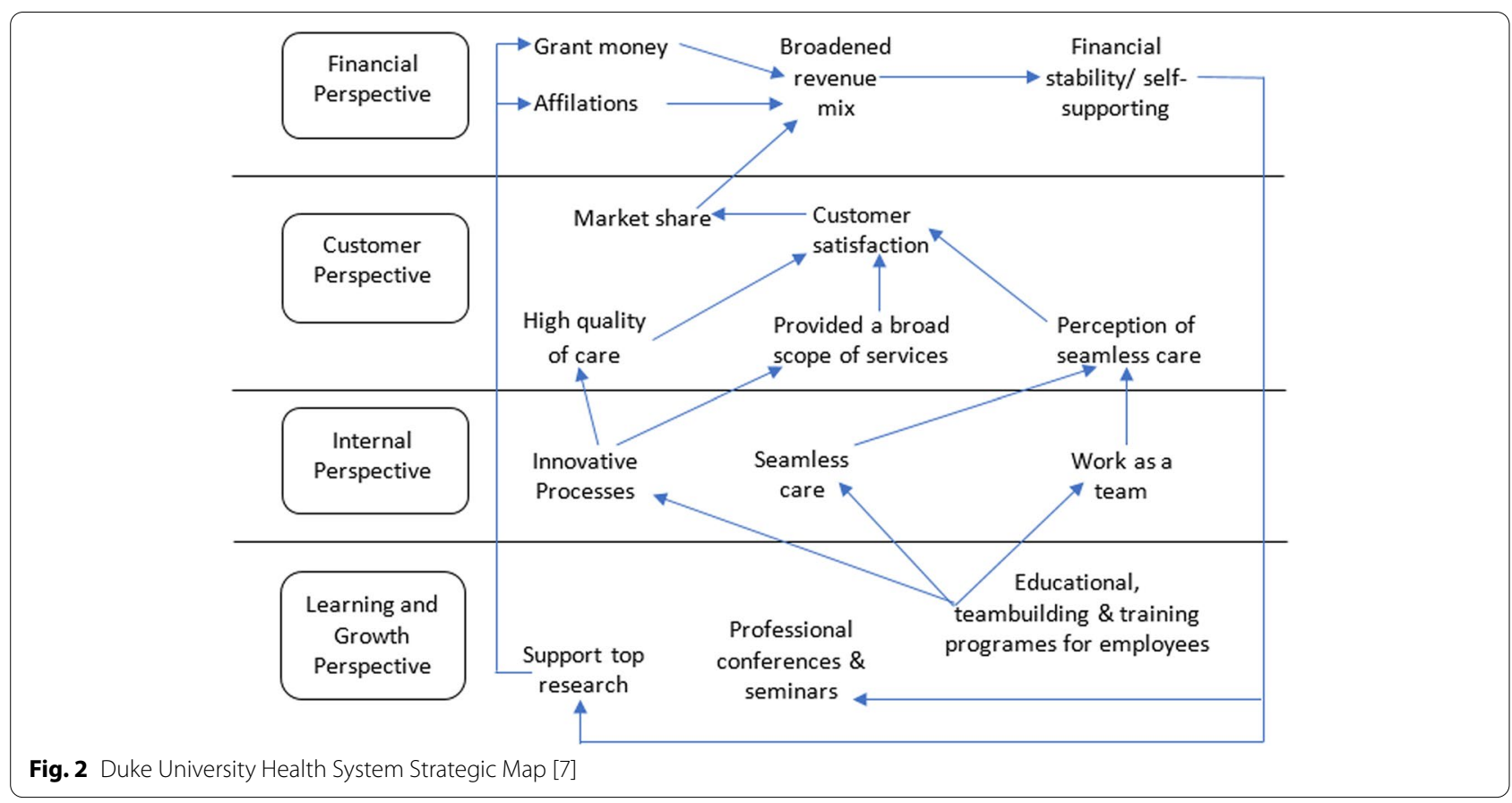

